\title{
'REVEALED COMMONALITY': LINKAGES IN CONSUMPTION, INVESTMENT AND OUTPUT IN EAST ASIA
}

\author{
Gordon de Brouwer and Mardi Dungey
}

\section{INTRODUCTION}

There is a growing appetite in East Asia for thinking about ways to deepen economic and financial policy dialogue, cooperation and integration. This paper aims to inform that debate by examining what data on output, consumption and investment in East Asia reveal about linkages and commonality in the region.

We apply time-series techniques to identify elements of commonality in East Asian output, consumption and investment data. We first set out the data we use for empirical analysis. US data are included to identify the relative importance of the United States to the region. We conduct four tests. First, we look for common trends in the variables using cointegration analysis. We then apply bivariate Granger-causality tests to output, consumption and investment growth to identify the short-run commonality in economic cycles in the region. We conduct latent factor analysis on growth rates in output, consumption and investment to identify common and idiosyncratic factors in these series. Finally, we look at the changing patterns and structure of correlations of consumption, purged of income effects, to measure financial integration in the region. As it turns out, these tests reveal much about the nature of linkages in the region.

\section{DATA}

The focus of this study is on the regional relationship between key macroeconomic variables in East Asia, specifically private consumption, total investment and output. In most cases, data are only available for a relatively short time period. Appendix 3.1 lists data sources.

Figures 3.1, 3.2 and 3.3 show quarterly seasonally-adjusted constant-price data for 12 countries for these three aggregates. The countries we look at are a subset of countries in the East Asian region: Australia, Hong Kong Special Administrative Region of China (Hong Kong SAR), Indonesia, Japan, Korea, Malaysia, New Zealand, the Philippines, Singapore, Taiwan Province of China (Taiwan) and Thailand. For comparability, we also include the United States. Group A economies are those for which data are available from March 1978, namely Australia, Hong Kong SAR, Japan, Korea, Singapore, Taiwan and the United States. Group B economies are those for which data are only available from at least March 1993. The graphs show the data as logs of the index of each series, where the index is set to 100 for the average value over the relevant time period (which means that the graphs will tend to show the series clumped together in the middle of the sample period).

The data in levels seem to show some common structure in their evolution. Each of the original data series, transformed into $\log$ form, displays unit root properties. For this reason most of the analysis in this paper is performed on the data in log differences. 
Figure 3.1: Private Consumption

Group A Economies

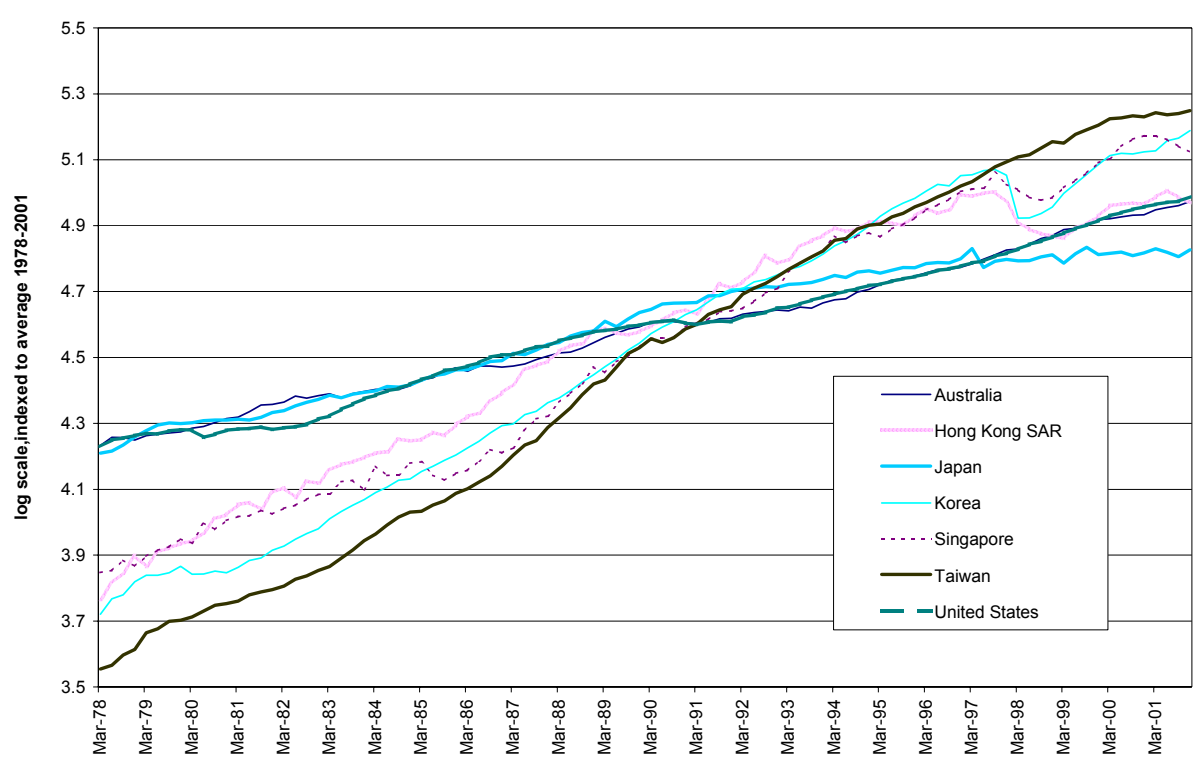

Group B Economies

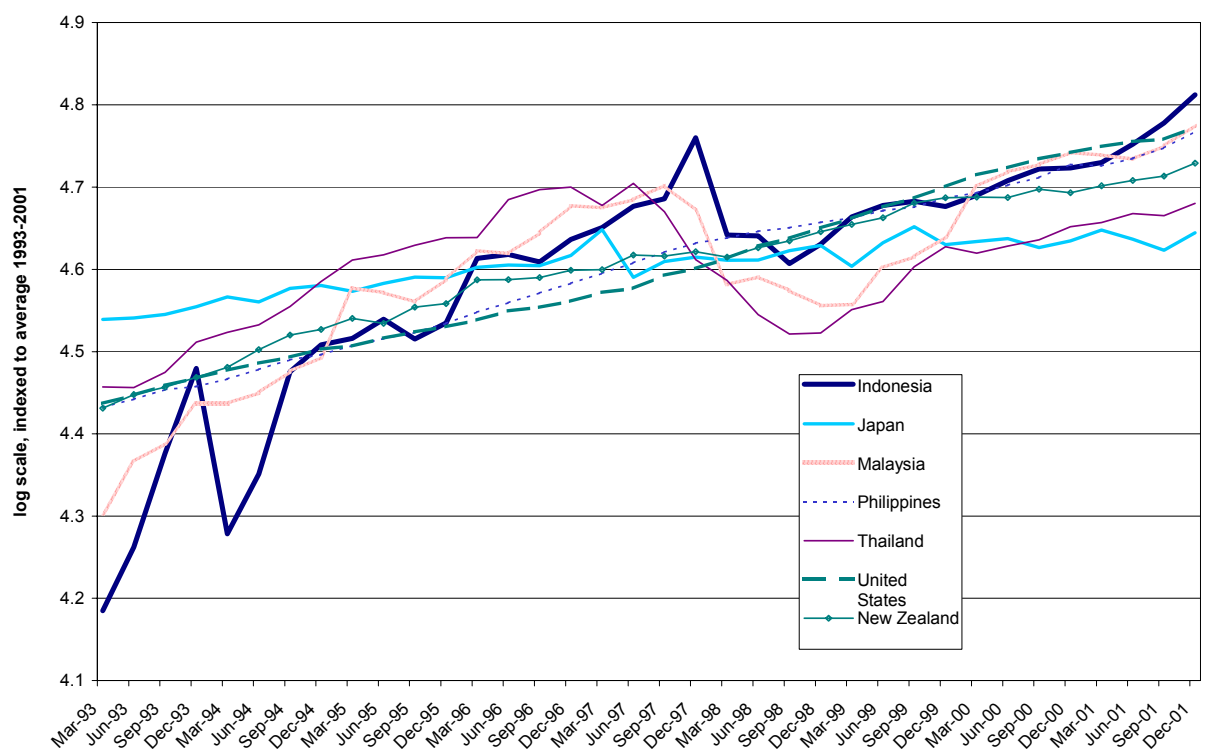

Source: CEIC database. 
Figure 3.2: Gross Fixed Capital Formation

Group A Economies

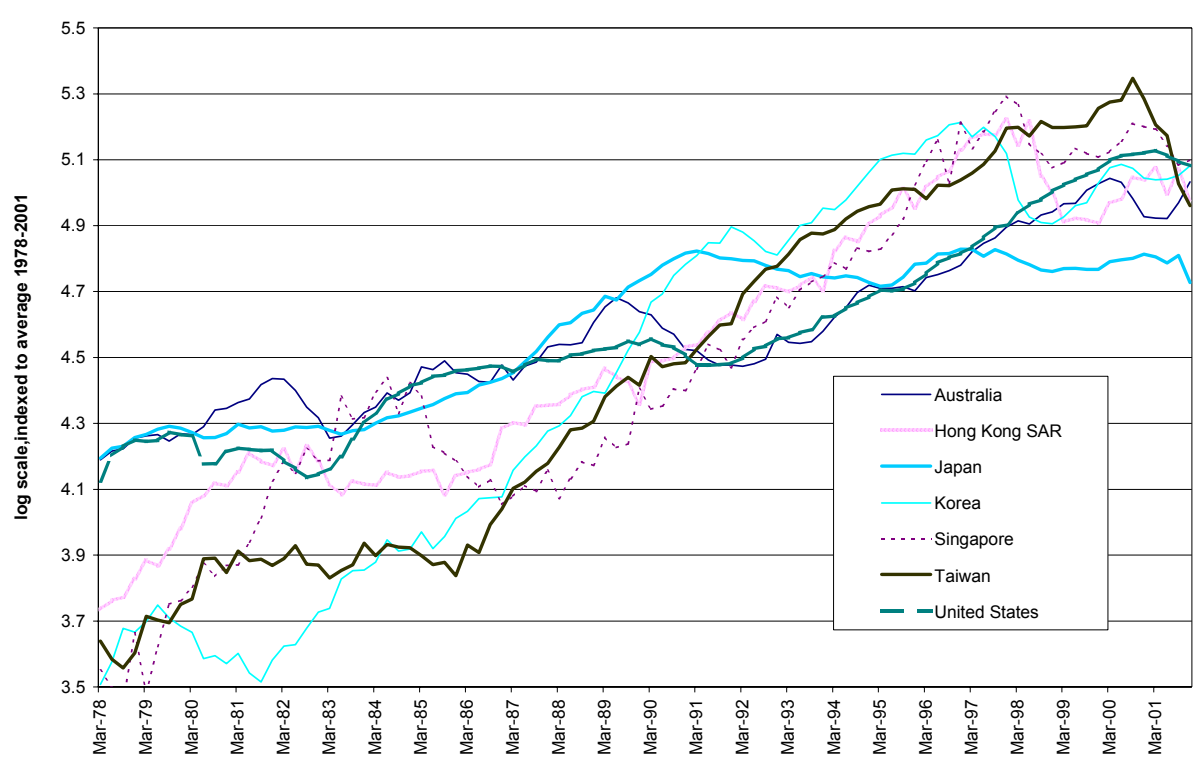

Group B Economies

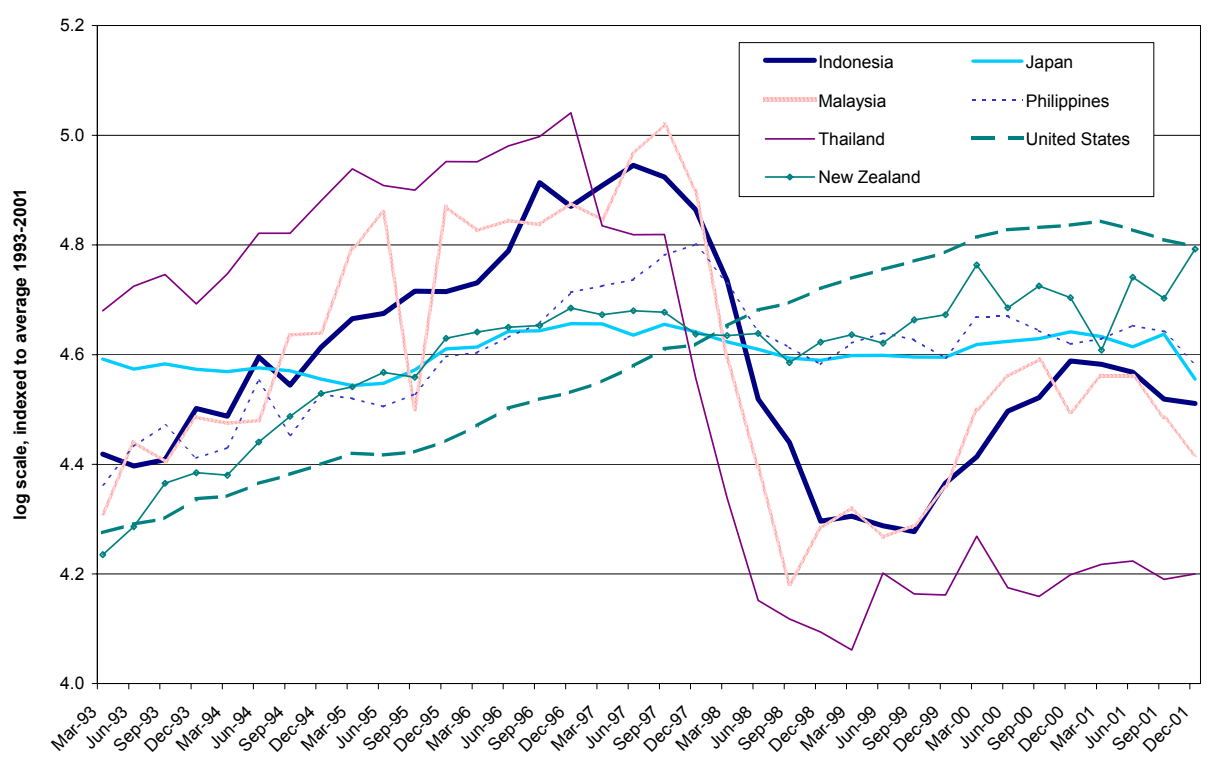

Source: CEIC database. 
Figure 3.3: Aggregate Output

Group A Economies

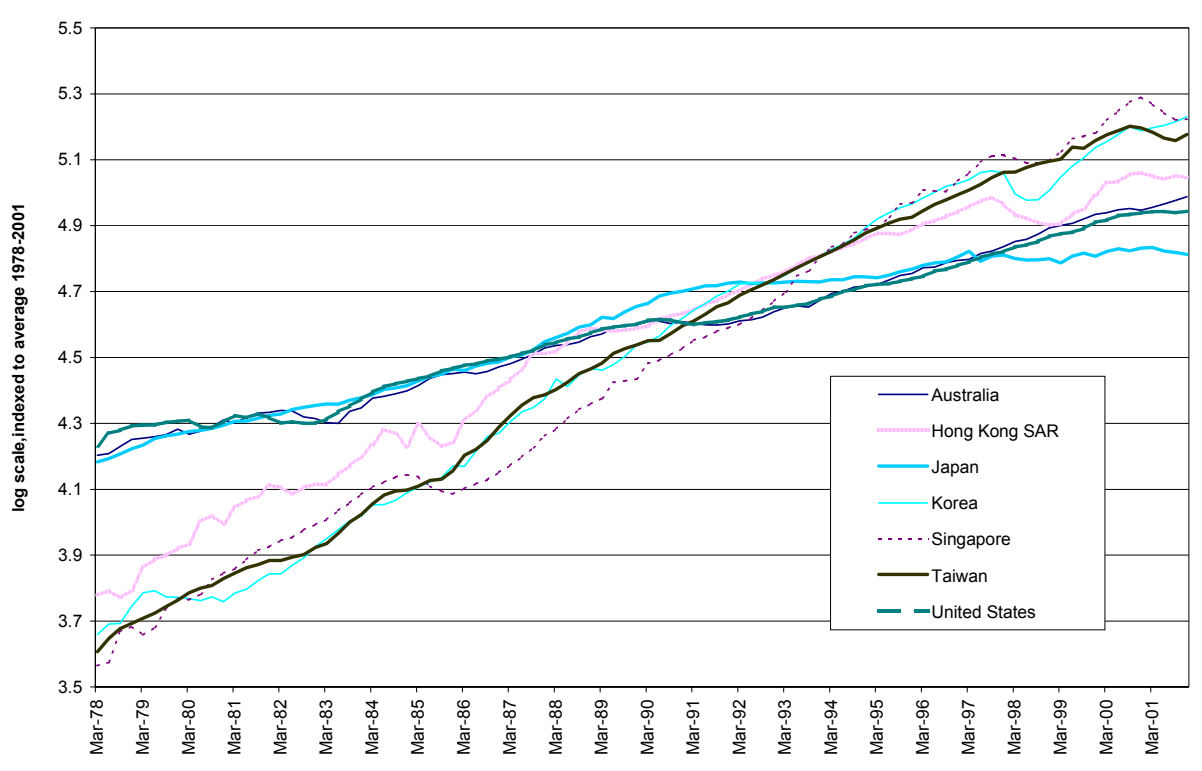

Group B Economies

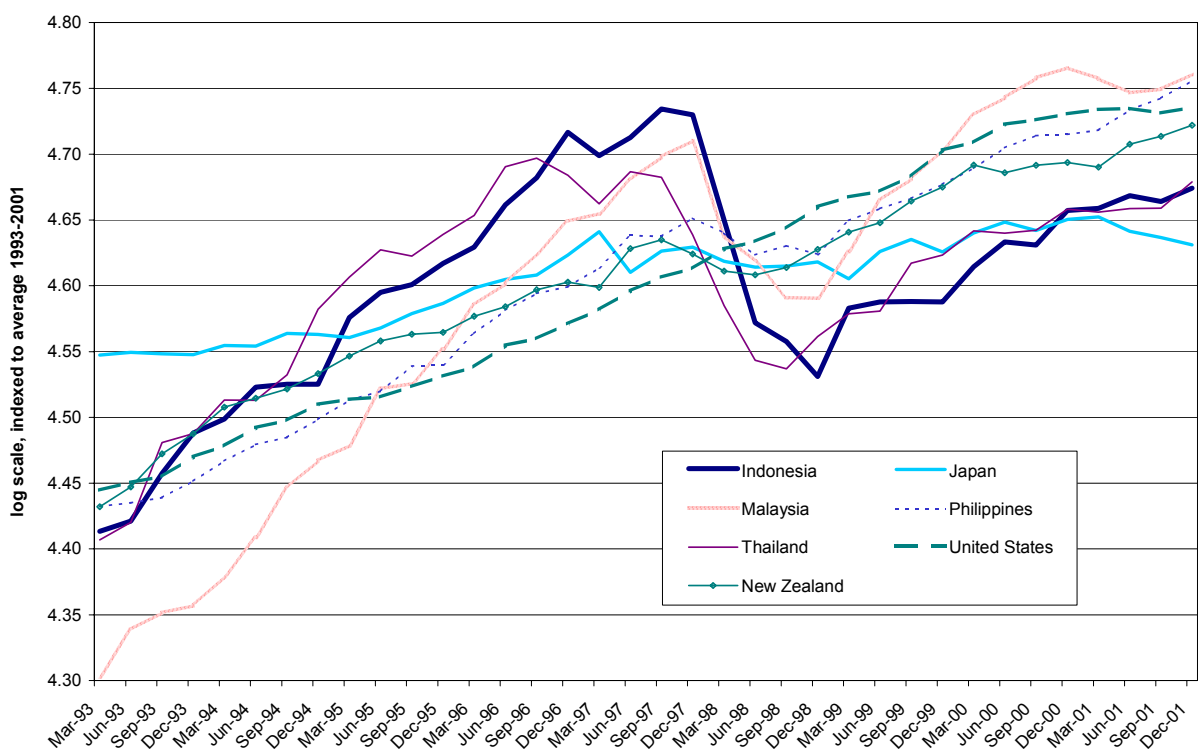

Source: CEIC database. 


\section{ASSESSING ECONOMIC CONVERGENCE AND INTEGRATION IN EAST} ASIA

There is a large empirical literature which seeks to identify common elements in macroeconomic time-series variables. This can have a range of motivations: whether countries have become more open, either in the economic or financial domain; whether economies have become more structurally similar over time; and whether structural similarity is at such a stage that these economies form a good basis for monetary integration.

Our motivation is simple: we wish to identify elements of commonness and difference in the region. This is partly data-based, using time-series techniques such as cointegration tests, Granger-causality tests, and latent factor analysis to identify short-term and longterm common elements in output, consumption and investment in East Asia. This enables us to identify common trends, common short-run business cycle features and common factors in these macroeconomic aggregates.

While our focus here is on 'letting the data speak', we do not regard this as atheoretical data analysis. Output, consumption and investment can be thought of as the outcomes of intentional actions (such as government policies and rules-based private decision-making) and unexpected events (shocks and disturbances). ${ }^{1}$ If a country's economy is the joint outcome of these systematic and non-systematic actions, then commonness between different economies arises because of commonness in these systematic and nonsystematic actions. The view that commonality in outcomes reveals commonality in fundamental economic structures and stochastic processes underpins our analysis of the data. We also apply a test of integration - consumption smoothing - in order to identify changes in the degree of financial integration in East Asia.

\section{Commonality in economic trends}

Given that the macroeconomic time series that we are assessing are non-stationary in levels, it is natural to start by looking at whether long-term relationships or common trends exist in the various aggregates between countries.

A number of studies have examined the relationship between output across countries. ${ }^{2}$ Bernard and Durlauf (1995), for example, propose a number of tests for convergence based on the time-series properties of output data. The first, which they call convergence in multivariate output, consists of checking for a cointegrating relationship between countries' output. In a bivariate case the restriction implies a cointegrating vector of [1,1] for each country pair. The less restrictive version of this test, which they dub common trends in multivariate output, tests for a proportional cointegrating relationship, so that each country pair has a cointegrating vector $[1, \alpha]$. We dub these tests more generally as multivariate convergence and multivariate trends respectively.

We test for convergence and common trends in output, consumption and investment for the seven Group A countries. In our estimations, we include three lags in the JohanensenJuselius vector autoregression (VAR) model used to test for cointegration, since we have quarterly data. $^{3}$ 
The results for output are shown in Table 1. Part A sets out the results for the number of cointegrating vectors. The possible number of statistically significant cointegrating vectors is shown in bold. With respect to output from 1978 to 2001, the trace statistic test indicates that there is at most one cointegrating equation.

Part B sets out the estimated cointegrating relations. The first line is the unrestricted cointegrating vector. The signs can be confusing since they are assigned with all variables written on the same side of the equation; that is, multiplied by the relevant variables, they sum to zero. To read as a more recognisable equation, the coefficients are progressively normalised on each of the variables. The normalisation matters, as shown by the two different results for the United States and Japan. ${ }^{4}$

Table 3.1: Cointegration of Output across Countries

Part A: Number of Cointegrating Vectors

\begin{tabular}{cccc}
\hline \hline Cointegrating vectors & Eigenvalue & Trace statistic & Critical value at 5 per cent \\
\hline None & 0.39 & $\mathbf{1 4 0 . 3}$ & 124.2 \\
At most 1 & 0.30 & $\mathbf{9 6 . 5}$ & 94.1 \\
At most 2 & 0.21 & 63.7 & 68.5 \\
At most 3 & 0.20 & 41.9 & 47.2 \\
At most 4 & 0.12 & 20.8 & 29.7 \\
\hline
\end{tabular}

Part B: Estimated Cointegrating Relations

\begin{tabular}{|c|c|c|c|c|c|c|c|}
\hline & USA & JPN & AUS & KOR & TWN & SNG & $\mathrm{HKG}$ \\
\hline Unrestricted cointegrating coefficients & 116.3 & -17.9 & -122.3 & -30.0 & 10.0 & 18.3 & 21.1 \\
\hline Normalised on US GDP & 1.00 & $\begin{array}{c}\mathbf{0 . 1 5} \\
(0.09)\end{array}$ & $\begin{array}{c}\mathbf{1 . 0 5} \\
(0.11)\end{array}$ & $\begin{array}{c}\mathbf{0 . 2 6} \\
(0.06)\end{array}$ & $\begin{array}{l}-0.09 \\
(0.14)\end{array}$ & $\begin{array}{l}-\mathbf{- 0 . 1 6} \\
(0.03)\end{array}$ & $\begin{array}{l}-\mathbf{0 . 1 8} \\
(0.05)\end{array}$ \\
\hline Normalised on Japanese GDP & $\begin{array}{c}6.51 \\
(1.44)\end{array}$ & 1.00 & $\begin{array}{l}-6.84 \\
(1.44)\end{array}$ & $\begin{array}{l}-1.68 \\
(0.44)\end{array}$ & $\begin{array}{c}0.56 \\
(0.75)\end{array}$ & $\begin{array}{c}1.02 \\
(0.28)\end{array}$ & $\begin{array}{c}1.18 \\
(0.34)\end{array}$ \\
\hline
\end{tabular}

Note: Bold indicates significant at the 5 per cent level; standard errors in parentheses.

The one cointegrating vector in Part B is first normalised on US GDP. There is a common positive trend between US GDP and GDP in Japan, Australia and Korea but, oddly, a negative one with GDP in Taiwan, Singapore and Hong Kong SAR. Only in the case of Taiwan is this not statistically significant. In the case of Australia, there is convergence with the United States; for Japan and Korea there is only a common trend.

The one cointegrating vector is then normalised on Japanese GDP. In this case, a rise in Japanese GDP is associated with a rise in GDP in the United States, Taiwan, Singapore and Hong Kong SAR, but with falls in GDP in Australia and Korea. Again, only in the case of Taiwan is this not statistically significant. Singapore and Hong Kong SAR converge with Japan; the United States, as before, only shares a common trend with Japan. The more striking result is that there is no convergence or positive common trend of Japanese output with that of Korea or Taiwan.

Consider now the results for consumption (Table 3.2) and investment (Table 3.3). In the case of consumption, there are at most two cointegrating vectors (Part A). In Part B of Table 3.2 we show the unrestricted cointegrating vectors and the equations normalised on US and Japanese consumption for both cointegrating vectors. ${ }^{5}$ In this case, US, Australian and Korean private consumption have a common factor (and indeed converge), but the consumption trend of Singapore and Hong Kong SAR with the United States is negative. Japan, Hong Kong SAR and Taiwan also share a common consumption factor, but that of Australia and Korea with Japan is negative. 
Table 3.2: Cointegration of Consumption across Countries

Part A: Number of Cointegrating Vectors

\begin{tabular}{cccc}
\hline \hline Cointegrating vectors & Eigenvalue & Trace statistic & Critical value at 5 per cent \\
\hline None & 0.40 & $\mathbf{1 7 1 . 7}$ & 124.2 \\
At most 1 & 0.36 & $\mathbf{1 2 4 . 5}$ & 94.2 \\
At most 2 & 0.33 & $\mathbf{8 3 . 4}$ & 68.5 \\
At most 3 & 0.24 & 47.1 & 47.2 \\
At most 4 & 0.16 & 22.2 & 29.7 \\
\hline
\end{tabular}

Part B: Estimated Cointegrating Relations

\begin{tabular}{|c|c|c|c|c|c|c|c|}
\hline & USA & JPN & AUS & KOR & TWN & SNG & HKG \\
\hline \multicolumn{8}{|c|}{ Unrestricted cointegrating coefficients } \\
\hline First cointegrating vector & 62.2 & 34.4 & -57.1 & -35.4 & -20.7 & 39.5 & 6.2 \\
\hline Second cointegrating vector & -37.7 & $-1,023.0$ & 9.6 & -21.1 & 69.3 & -27.3 & 29.0 \\
\hline \multicolumn{8}{|c|}{ Normalised on US or Japanese GDP } \\
\hline First cointegrating vector & 1.00 & & $\begin{array}{c}1.09 \\
(0.16)\end{array}$ & $\begin{array}{c}0.86 \\
(0.14)\end{array}$ & $\begin{array}{l}-0.05 \\
(0.14)\end{array}$ & $\begin{array}{l}-0.61 \\
(0.10)\end{array}$ & $\begin{array}{r}-0.32 \\
(0.09)\end{array}$ \\
\hline Second cointegrating vector & & 1.00 & $\begin{array}{r}-0.31 \\
(0.12)\end{array}$ & $\begin{array}{l}-0.52 \\
(0.10)\end{array}$ & $\begin{array}{c}0.69 \\
(0.10)\end{array}$ & $\begin{array}{c}-0.03 \\
(0.08)\end{array}$ & $\begin{array}{c}0.40 \\
(0.06)\end{array}$ \\
\hline
\end{tabular}

Note: Bold indicates significant at the 5 per cent level; standard errors in parentheses.

In the case of investment, there are at most three cointegrating vectors in our sevencountry sample set (Table 3.3, Part A). In Part B of Table 3.3 we show the unrestricted cointegrating vectors and the equations normalised on US, Japanese and Korean investment for the three cointegrating vectors. ${ }^{6}$ US investment has a common positive trend with that of Australia and Hong Kong SAR (as well as Korea). Japanese investment has a common positive trend with that of Singapore. And Korean investment has a common positive trend with that of Taiwan and Hong Kong SAR.

Table 3.3: Cointegration of Investment across Countries

Part A: Number of Cointegrating Vectors

\begin{tabular}{cccc}
\hline \hline Cointegrating vectors & Eigenvalue & Trace statistic & Critical value at 5 per cent \\
\hline None & 0.43 & $\mathbf{1 5 5 . 4}$ & 124.2 \\
At most 1 & 0.29 & $\mathbf{1 0 4 . 4}$ & 94.2 \\
At most 2 & 0.23 & $\mathbf{7 3 . 1}$ & 68.5 \\
At most 3 & 0.21 & $\mathbf{4 9 . 6}$ & 47.2 \\
At most 4 & 0.16 & 28.0 & 29.7 \\
\hline
\end{tabular}

Part B: Estimated Cointegrating Relations

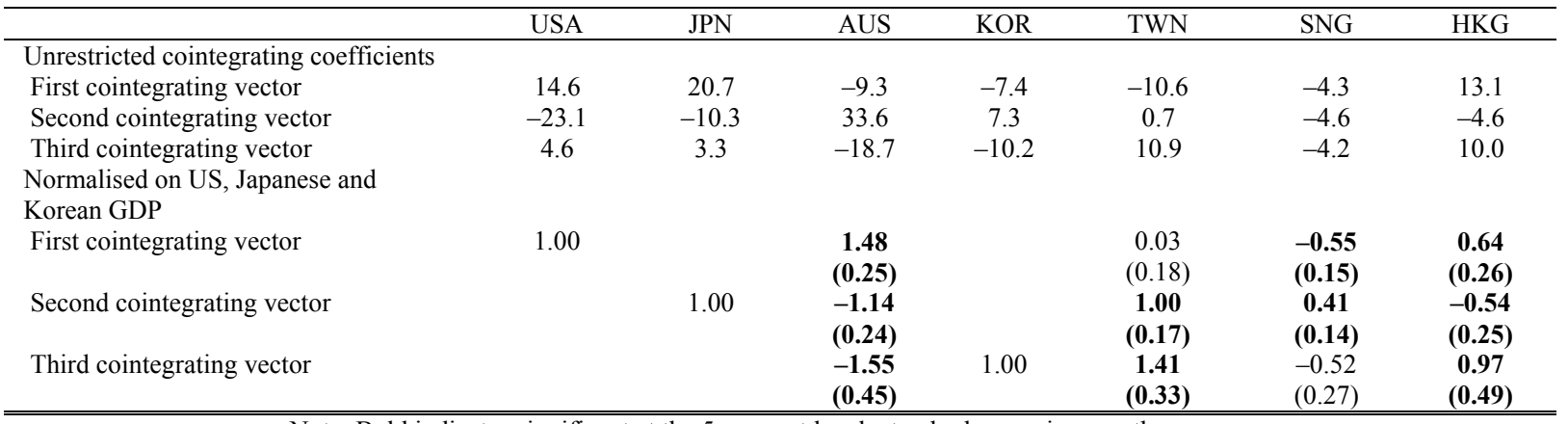

Note: Bold indicates significant at the 5 per cent level; standard errors in parentheses.

\section{Commonality in short-run economic cycles}

We now look at the short-run interaction between consumption, investment and output in different countries in East Asia by testing for Granger-causality between the growth rates in these variables between countries. Granger-causality is not a test of 'causality' as the 
ordinary person in the street would define it, but rather a test of whether one variable has information useful in forecasting the other. In this context it provides information on whether there is information from the cycle in one country's private consumption, investment or output that can be used to explain that of the same variable in another country. The null hypothesis is Granger-non-causality, which is tested using vector autoregressions of the first difference in natural logarithms with two lags. Tables 3.4, 3.5 and 3.6 present results of Granger causality tests for the Group A countries over the sample period March 1978 to December 2001.

Most of the pairs of data examined do not reject the null hypothesis of Granger-noncausality. This is particularly true of the consumption data (Table 3.4). This is not especially surprising, since consumption is well documented as one of the most 'smooth' economic time series and substantially more resilient to external shocks than is domestic income in general. ${ }^{8}$

There is little evidence of Granger-causality between growth rates in consumption across pairs of countries. Innovations in consumption in the big economies, such as Japan or the United States, do not systematically lead the innovations in consumption in other countries in East Asia. The strongest relationship for this sample period and data set is that changes in consumption in Taiwan tend to lead those in Japan and Singapore. In both cases the sign is positive on both lags of Taiwanese consumption growth, although only the first lag is statistically significant.

Table 3.4: Granger Causality on Consumption Growth Rates, 1978-2001 (probability value of the null hypothesis that the variable listed on the left-hand side does not Granger-cause the variable listed in the top row)

\begin{tabular}{lccccccc}
\hline & AUS & JPN & USA & KOR & SNG & TWN & HKG \\
\hline AUS & & 0.65 & 0.66 & 0.96 & 0.11 & 0.11 & 0.26 \\
JPN & 0.71 & & 0.70 & 0.86 & 0.14 & 0.76 & 0.30 \\
USA & 0.26 & 0.94 & & 0.72 & 0.70 & 0.23 & 0.61 \\
KOR & 0.22 & 0.14 & 0.66 & & $\mathbf{0 . 0 7}$ & 0.35 & 0.11 \\
SNG & 0.35 & 0.28 & 0.83 & $\mathbf{0 . 0 6}$ & & & $\mathbf{0 . 0 5}$ \\
TWN & 0.67 & $\mathbf{0 . 0 1}$ & 0.79 & 0.65 & $\mathbf{0 . 0 1}$ & 0.24 & 0.21 \\
HKG & 0.55 & 0.75 & 0.17 & 0.52 & 0.20 & 0.41 & \\
\hline \hline
\end{tabular}

Note: Bold indicates that the null hypothesis that variable $x$ does not Granger-cause variable $y$ is rejected at the 10 per cent level.

In the case of investment (Table 3.5), there are more systematic relationships between pairs of countries. Hong Kong SAR is the economy whose investment is most predicted by investment growth from other economies, with changes in investment in Japan, Korea and Singapore tending to lead Hong Kong SAR investment growth. Changes in Korea and Taiwan also tend to lead those in Japan. Changes in investment in the United States only systematically lead investment growth in Australia in this sample.

There are more Granger-causality relationships between country pairs of aggregate output (Table 3.6). Of the countries included in the sample, Hong Kong SAR is the economy whose output growth can be most clearly predicted by a range of other Asia Pacific economies, notably the United States, Korea, Singapore and Taiwan. Japanese output growth is also predicted by the same set of countries, apart from the United States. As is 
well documented, US growth helps predict Australian growth. ${ }^{9}$ What is striking overall is that the big economies, notably the United States and Japan, do not tend to lead growth, be it in consumption, investment or aggregate output, elsewhere in East Asia.

Table 3.5: Granger Causality on Investment Growth Rates, 1978-2001

(probability value of the null hypothesis that the variable listed on the left-hand side does not Granger-cause the variable listed in the top row)

\begin{tabular}{cccccccc}
\hline \hline & AUS & JPN & USA & KOR & SNG & TWN & HKG \\
\hline AUS & & 0.70 & 0.44 & 0.78 & 0.12 & 0.33 & 0.55 \\
JPN & 0.66 & & 0.26 & 0.47 & 0.42 & 0.49 & $\mathbf{0 . 0 5}$ \\
USA & $\mathbf{0 . 0 4}$ & 0.85 & & 0.39 & 0.89 & 0.38 & 0.95 \\
KOR & 0.15 & $\mathbf{0 . 0 3}$ & 0.60 & & 0.26 & $\mathbf{0 . 0 4}$ & $\mathbf{0 . 0 3}$ \\
SNG & 0.37 & 0.34 & 0.78 & 0.47 & & 0.13 & $\mathbf{0 . 0 0}$ \\
TWN & 0.33 & $\mathbf{0 . 0 5}$ & 0.46 & 0.70 & $\mathbf{0 . 0 9}$ & & 0.21 \\
HKG & 0.84 & 0.47 & $\mathbf{0 . 0 5}$ & 0.11 & 0.59 & $\mathbf{0 . 0 8}$ & \\
\hline \hline
\end{tabular}

Note: Bold indicates that the null hypothesis that variable $x$ does not Granger-cause variable $y$ is rejected at the 10 per cent level.

Table 3.6: Granger Causality on GDP Growth Rates, 1978-2001

(probability value of the null hypothesis that the variable listed on the left-hand side does not Granger-cause the variable listed in the top row)

\begin{tabular}{lccccccc}
\hline \hline & AUS & JPN & USA & KOR & SNG & TWN & HKG \\
\hline AUS & & 0.19 & $\mathbf{0 . 0 0}$ & 0.91 & 0.49 & 0.48 & 0.83 \\
JPN & 0.64 & & 0.80 & 0.41 & 0.57 & 0.67 & 0.23 \\
USA & $\mathbf{0 . 0 0}$ & 0.81 & & 0.67 & 0.78 & 0.15 & $\mathbf{0 . 0 7}$ \\
KOR & 0.64 & $\mathbf{0 . 0 0}$ & 0.76 & & 0.14 & 0.15 & $\mathbf{0 . 0 1}$ \\
SNG & 0.77 & $\mathbf{0 . 0 0}$ & 0.60 & 0.23 & & 0.45 & $\mathbf{0 . 0 5}$ \\
TWN & 0.51 & $\mathbf{0 . 0 2}$ & 0.31 & 0.14 & 0.22 & & $\mathbf{0 . 0 1}$ \\
HKG & 0.36 & 0.23 & $\mathbf{0 . 0 2}$ & 0.80 & 0.21 & 0.32 & \\
\hline \hline
\end{tabular}

Note: Bold indicates that the null hypothesis that variable $x$ does not Granger-cause variable $y$ is rejected at the 10 per cent level.

This result also holds when the sample period is isolated to 1993-2001 and data for more ASEAN countries are included. As shown in Table 3.7, output growth in the United States and Japan leads growth in few countries in the region. Over this sample period, rather, growth in Korea has tended to lead that elsewhere in the region, especially in Southeast Asia. The countries with the most autonomous cycles are Korea, New Zealand, Australia, Singapore, Taiwan and the United States. Japan appears to be the country whose economic cycle is most widely predicted by that of other countries in the region, with growth in virtually every other country in the region helping to predict Japanese growth in this period. This has a number of possible interpretations: it may reflect the feedback effects of the East Asian financial crisis on Japan; or it may just be spurious in the sense that turning points in Japan's economic cycle have purely coincidentally been pre-dated by shocks to emerging East Asia. 
Table 3.7: Granger Causality on GDP Growth Rates, 1993-2001

(probability value of the null hypothesis that the variable listed on the left-hand side does not Granger-cause the variable listed in the top row)

\begin{tabular}{lllllllllllll}
\hline \hline & AUS & JPN & USA & KOR & SNG & TWN & HKG & IDN & MAL & NZL & PHL & THL \\
\hline AUS & & 0.78 & 0.47 & 0.90 & 0.79 & $\mathbf{0 . 0 3}$ & 0.21 & 0.98 & 0.23 & 0.45 & 0.91 & 0.67 \\
JPN & 0.46 & & $\mathbf{0 . 0 2}$ & 0.49 & 0.49 & 0.20 & $\mathbf{0 . 0 0}$ & 0.96 & 0.79 & 0.30 & $\mathbf{0 . 0 8}$ & 0.73 \\
USA & 0.89 & 0.56 & & 0.58 & 0.21 & 0.34 & $\mathbf{0 . 0 2}$ & 0.75 & 0.36 & 0.18 & 0.97 & 0.77 \\
KOR & 0.50 & $\mathbf{0 . 0 2}$ & 0.94 & & $\mathbf{0 . 0 8}$ & 0.59 & $\mathbf{0 . 0 5}$ & $\mathbf{0 . 0 0}$ & $\mathbf{0 . 0 0}$ & $\mathbf{0 . 0 1}$ & $\mathbf{0 . 0 0}$ & $\mathbf{0 . 0 2}$ \\
SNG & $\mathbf{0 . 0 6}$ & $\mathbf{0 . 0 2}$ & 0.35 & 0.71 & & 0.53 & 0.55 & 0.74 & 0.89 & 0.69 & 0.80 & 0.28 \\
TWN & 0.98 & $\mathbf{0 . 0 4}$ & $\mathbf{0 . 0 2}$ & 0.55 & 0.26 & & 0.30 & 0.40 & 0.98 & 0.59 & 0.58 & $\mathbf{0 . 0 7}$ \\
HKG & 0.44 & $\mathbf{0 . 0 4}$ & 0.70 & 0.74 & 0.12 & 0.22 & & $\mathbf{0 . 0 0}$ & $\mathbf{0 . 0 3}$ & 0.32 & $\mathbf{0 . 0 4}$ & $\mathbf{0 . 0 5}$ \\
IDN & 0.56 & $\mathbf{0 . 0 0}$ & 0.79 & 0.25 & 0.26 & 0.29 & 0.90 & & 0.38 & 0.63 & $\mathbf{0 . 0 6}$ & 0.36 \\
MAL & 0.31 & $\mathbf{0 . 0 0}$ & 0.76 & 0.44 & 0.17 & 0.31 & 0.30 & 0.13 & & 0.91 & $\mathbf{0 . 0 1}$ & 0.78 \\
NZL & 0.78 & 0.14 & 0.76 & 0.35 & 0.16 & 0.21 & 0.58 & $\mathbf{0 . 0 0}$ & $\mathbf{0 . 0 3}$ & & 0.11 & 0.55 \\
PHL & 0.44 & $\mathbf{0 . 0 3}$ & 0.60 & 0.19 & 0.96 & 0.49 & 0.24 & 0.72 & 0.22 & 0.69 & & 0.50 \\
THL & 0.89 & $\mathbf{0 . 0 6}$ & 0.26 & $\mathbf{0 . 0 3}$ & 0.18 & 0.62 & 0.35 & $\mathbf{0 . 0 0}$ & $\mathbf{0 . 0 1}$ & 0.21 & $\mathbf{0 . 0 0}$ & \\
\hline \hline
\end{tabular}

Note: Bold indicates that the null hypothesis that variable $x$ does not Granger-cause variable $y$ is rejected at the 10 per cent level.

\section{Commonality in latent factors}

Further insights about commonality in East Asia may be provided by identifying common latent factors in the macroeconomic time series focused on in this paper. The economies looked at in this section are the Group A countries: Australia, Japan, Korea, Singapore, Hong Kong SAR, Taiwan and the United States. ${ }^{10}$

Consider a simple two-factor model of each of the variables $y_{i, t}$

$$
y_{i, t}=\phi_{i} S_{i, t}+\lambda_{i} W_{t}
$$

where $y_{i, t}$ is the difference in the growth rates of the particular economic aggregate or fundamental -consumption, investment or output - in country $i$ and a benchmark country. ${ }^{11}$ That is,

$$
y_{i, t}=\Delta Y_{i, t}-\Delta Y_{\text {benchmark }, t}
$$

where $Y_{i, \mathrm{t}}$ is the log level of the economic variable in country $i$ and the benchmark is growth in the US and Japanese economic variable in successive estimations. Benchmarking growth in this way reduces the number of variables in estimation and, as explained below, the number of over-identifying restrictions. It also draws attention to possible differences in US and Japanese influence on consumption, investment and output growth in East Asia.

The latent factor, $W_{t}$, represents the effect common to the difference in growth rates across countries, and the other latent factor, $S_{i, t}$, represents the idiosyncratic factor unique to each variable in country $i$. The loadings on these factors are given by the parameters $\lambda_{i}$ and $\phi_{i}$. Under the assumption that all the factors are independent, and normalising the factor variances, this model can simply be estimated from second moment conditions using a Generalised Method of Moments (GMM) estimator, in a two-factor version of the model presented in Dungey (1999). 
The normalisation of the variances means that the estimated factor loadings are not themselves particularly interesting. However, the variance decomposition is not affected by the normalisation, and so we can consider the contribution of the common and country-specific factors for each economic aggregate. The unconditional variance of the difference in growth rates of the economic aggregate or fundamental, $y_{i, t}$, can be written as

$$
\operatorname{var}\left(y_{i}\right)=\lambda_{i}^{2}+\phi_{i}^{2}
$$

The proportion of the total variance in $y_{i, t}$ given by the common factor is the ratio of the first term to the total. The proportion given by the idiosyncratic factor is the remainder.

Identification of this model relies on a sufficiently large panel of data on the fundamental data - and this is why we are restricted to looking at our Group A economies. In matrix form, Equation (1) is written as:

$$
\mathrm{Y}_{t}=\Phi \mathrm{S}_{t}+\mathrm{K} W_{t}
$$

where $\mathbf{Y}_{t}$ is an $n \times 1$ vector of data on the growth rate differences across $n$ countries at time $t, \Phi$ is an $n \times n$ diagonal matrix containing the loadings on the country-specific factors, which are themselves contained in the $n \times 1$ vector $\mathbf{S}_{t}$, and $\mathbf{K}$ is an $n \times 1$ vector of loadings on the common factor, $W_{t}$. There are $n$ unknown elements in $\Phi$, and $n$ in $\mathbf{K}$. Estimation of the model from variance-covariance conditions requires the following identification condition:

$$
2 n \leq \frac{n(n+1)}{2} \Rightarrow n \geq 3
$$

That is, data on at least three economies are necessary to identify the parameters. In the case of three countries the system is exactly identified. In the case of seven economies (but six variables because growth is benchmarked), as put forward here, the system is over-identified, with 21 moment conditions to identify 12 parameters. In this case, the standard Hansen (1982) procedure for estimating over-identified systems in GMM is applied.

Table 3.8 presents the simple factor model decompositions for common and countryspecific factors for output, consumption and investment growth in Parts A, B and C respectively, benchmarked on growth in the corresponding US and Japanese aggregate. Benchmarking means that a country's growth rates enter the estimation as its ( $i$ th) growth rate less that of the benchmark country. Figure 3.4 shows the common factor contribution to output, consumption and investment for each of the benchmark cases.

There are two key results from this factor analysis. 
Table 3.8: Simple Factor Model Variance Decomposition

A. Output Growth

\begin{tabular}{lcccc}
\hline \hline & & \multicolumn{2}{c}{ Benchmarked on } \\
& \multicolumn{2}{c}{ US output growth } & \multicolumn{2}{c}{ Japanese output growth } \\
& Common factor & Idiosyncratic factor & Common factor & Idiosyncratic factor \\
\hline Australia & 10.8 & 89.2 & 52.1 & \\
Japan & 51.5 & 48.5 & 37.5 & 62.5 \\
Korea & 33.3 & 66.7 & 15.8 & 84.2 \\
HKSAR & 68.5 & 31.5 & 42.2 & 57.8 \\
Singapore & 23.1 & 76.9 & 91.7 & 8.3 \\
Taiwan & 46.9 & 53.1 & 69.0 & 31.0 \\
United States & & & & \\
\hline \hline
\end{tabular}

\section{B. Consumption Growth}

\begin{tabular}{lcccc}
\hline \hline & & \multicolumn{2}{c}{ Benchmarked on } \\
& \multicolumn{2}{c}{ US consumption growth } & \multicolumn{2}{c}{ Japanese consumption growth } \\
& Common factor & Idiosyncratic factor & Common factor & Idiosyncratic factor \\
\hline Australia & 27.1 & 72.9 & 75.1 & \\
Japan & 21.5 & 78.5 & 86.8 & 13.2 \\
Korea & 22.1 & 77.9 & 32.4 & 67.6 \\
HKSAR & 23.2 & 76.8 & 33.2 & 66.8 \\
Singapore & 46.8 & 53.2 & 65.9 & 34.1 \\
Taiwan & 49.6 & 50.4 & 86.8 & 13.2 \\
United States & & & & \\
\hline \hline
\end{tabular}

\begin{tabular}{|c|c|c|c|c|}
\hline & \multicolumn{4}{|c|}{ Benchmarked on } \\
\hline & \multicolumn{2}{|c|}{ US investment growth } & \multicolumn{2}{|c|}{ Japanese investment growth } \\
\hline & Common factor & Idiosyncratic factor & Common factor & Idiosyncratic factor \\
\hline Australia & 4.5 & 95.5 & 51.0 & 49.0 \\
\hline Japan & 66.3 & 33.7 & & \\
\hline Korea & 35.6 & 64.4 & 7.8 & 92.2 \\
\hline HKSAR & 19.2 & 80.8 & 0.8 & 99.2 \\
\hline Singapore & 9.2 & 90.8 & 3.2 & 96.8 \\
\hline Taiwan & 15.0 & 85.0 & 5.9 & 94.1 \\
\hline United States & & & 60.3 & 39.7 \\
\hline
\end{tabular}

Source: Authors' calculations.

\section{Similarities and differences in East Asia}

The first is that the decompositions of growth in key macroeconomic variables into common and idiosyncratic factors can vary substantially between countries within East Asia. At least with respect to factor analysis, East Asia looks to be a complex and heterogeneous entity.

Heterogeneity is shown most strikingly in the differences in the size and spread of the common factor when economies in the region are benchmarked to the United States and Japan. Benchmarking is important. Benchmarking against the United States effectively 'washes out' and excludes direct US effects from the common factor. Similarly, benchmarking against Japan effectively washes out and excludes direct Japanese effects from the common factor. Given that this is the only difference between the two data sets, we can use this information to draw conclusions about the relative importance of common Japanese and US effects in the region. This is important because the common factors are typically very different when East Asian output, consumption and investment growth rates are benchmarked on each of these major world economies. 
Figure 3.4: Contribution of the Common Factor

\section{A: Output Growth}

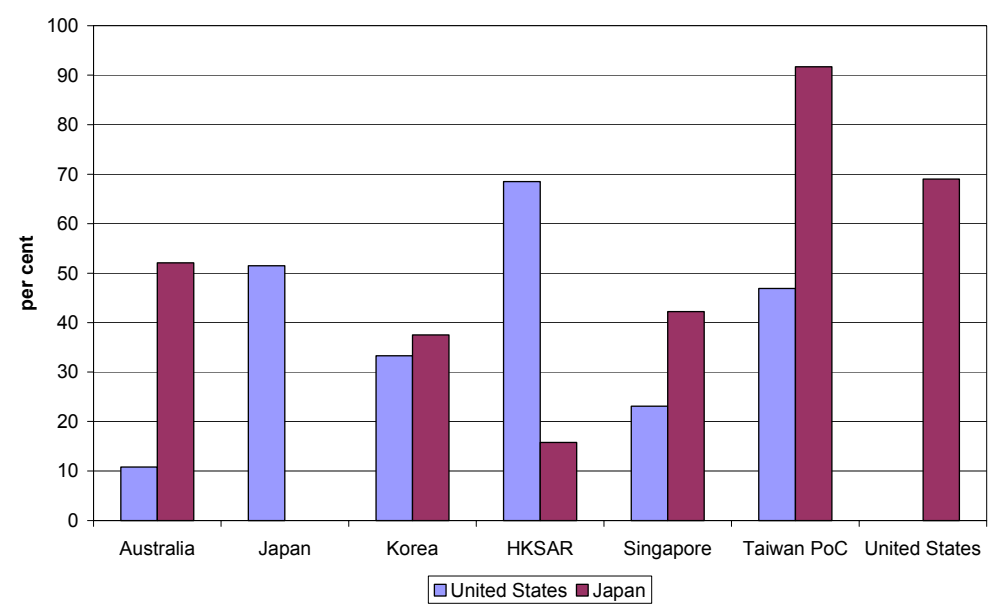

B: Consumption Growth

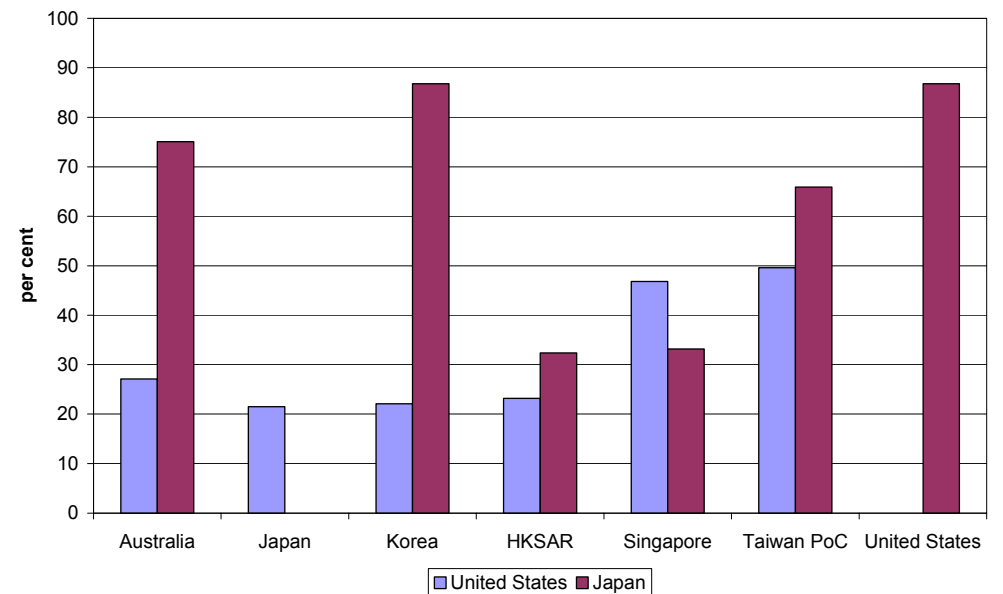

C: Investment Growth

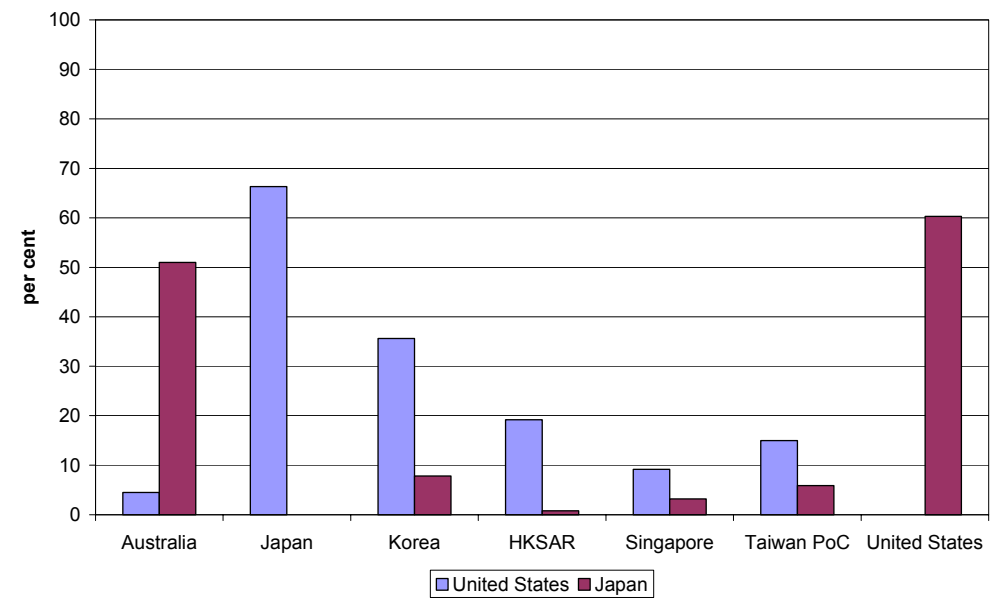

Note: Legend refers to benchmark for growth rate, thereby excluding the direct effect of the benchmark country in the common factor.

When the United States is the benchmark, the common factors in output are substantially lower for Australia, Singapore and Taiwan than when Japan is the benchmark: output 
growth in Australia, ${ }^{12}$ Singapore and Taiwan has had more in common with that in the United States than Japan over the past few decades. The common factor in output is similar for Korea for both benchmarks: Korea shares as much in common with both the United States and Japan. The common factor in output for Hong Kong SAR is much higher for the US benchmark than for the Japanese benchmark: Hong Kong SAR's output growth shares much more with in common with Japan than the United States. In terms of output growth, East Asia is diverse and subject to global influences, notably that of the United States.

While output growth in most of the economies in our East Asian sample has substantially more in common with that in the United States than in Japan, the opposite is true for investment growth. Apart from Australia, the economies in our sample share more in common with Japanese investment growth. This corresponds well with Japan's pattern of foreign direct investment, which is extensive in most of East Asia. Whereas Korean output growth shares equally sized common factors with Japan and the United States, Korean investment growth has much more in common with investment growth in Japan than that in the United States. While the common factors in East Asian investment growth are dominated by Japan rather than the United States, it is worth noting that the common factors in investment growth are, overall, much smaller than for output and consumption growth; that is, investment growth is substantially more idiosyncratic than output growth. (We examine this issue in more detail below.) Japanese investment in Australia is smaller than that of the United States, which is the largest country investor in Australia (and conversely, the United States is Australia's largest destination of overseas investment).

For the consumption decompositions, the results suggest that Australia, Korea and Taiwan have more in common with US consumption (that is, the common factors against the Japanese benchmark are larger) than with Japanese. The opposite is suggested for Hong Kong and Singapore.

\section{Differences between output, consumption and investment}

The second key result is that output, consumption and investment growth rates tend to vary across countries and across benchmarks with respect to commonness and idiosyncrasy. Consumption growth tends to have stronger common factors than output and investment growth, and investment has weaker common factors than output. Stated equivalently, consumption growth is the least idiosyncratic of the three macroeconomic variables while investment growth is the most.

This outcome has plausible economic explanations. The greater idiosyncrasy of investment relative to output and consumption is not surprising if investment is influenced by 'animal spirits'. What our results indicate is that business sentiment depends largely on domestic local events and prospects, at least for our set of economies.

The smoothness of consumption relative to output is well documented, and it implies that shocks or disturbances affect consumption less. This is not surprising if consumers are forward-looking and can use financial markets and other devices to smooth consumption in the presence of temporary disturbances to current income. The ability to smooth consumption is shared between our group of countries and, as suggested by the results found here, this is associated with greater commonness across countries in changes to 
consumption. Obstfeld (1994) examines the international dimensions of consumption smoothing and we address these issues later.

\section{Comparison with other studies}

Kose, Otrok and Whiteman (2000) conduct latent factor analysis of output, consumption and investment growth using data from the Penn World Tables from 1960 to 1991. They apply a latent factor model of global, regional and country factors to 60 economies. Given that our application applies only to the Asian region, the regional factor is subsumed in our application into the world common factor.

They obtain two key findings that are relevant to our study. First, they find that there is a common world factor, for which our evidence is consistent. Second, they find that the world (and regional) factor is more important for output than for consumption. Our evidence on this is more mixed. While the simple average of the world contribution for output is larger than for consumption, this is not as consistent across the countries in our sample as it is in Kose, Otrok and Whiteman. However, our evidence also strongly supports their result that investment is more determined by idiosyncratic factors than the other variables. These results are consistent with the long-term relationships examined above. The implication of having common trends in the data (as for consumption and GDP) is that country-specific effects should be less important than for data without common trends (investment). This is exactly the comparison found in the short-term data.

To make the comparison with Kose, Otrok and Whiteman more specific, Table 3.9 specifies the corresponding results from their paper, compiled by assigning the common factor to be the total of their world and regional factors, and the remainder to country factors. This is the correct equivalent of their model to our specification. The results in Table 3.9 show that although we can make similar generalisations to Kose, Otrok and Whiteman - as above - the results for the particular countries vary widely, which is a good illustration of the sensitivity of this type of exercise to the countries and time period included.

Table 3.9: Comparative Results for the Common Factor Contribution

\begin{tabular}{|c|c|c|c|c|c|c|c|c|c|}
\hline & \multicolumn{3}{|c|}{$\begin{array}{l}\text { GDP } \\
\end{array}$} & \multicolumn{3}{|c|}{ Consumption } & \multicolumn{3}{|c|}{ Investment } \\
\hline & $\begin{array}{c}\text { US } \\
\text { benchmark }\end{array}$ & $\begin{array}{c}\text { Japan } \\
\text { benchmark }\end{array}$ & Kose et al. & $\begin{array}{c}\text { US } \\
\text { benchmark }\end{array}$ & $\begin{array}{c}\text { Japan } \\
\text { benchmark }\end{array}$ & Kose et al. & $\begin{array}{c}\text { US } \\
\text { benchmark }\end{array}$ & $\begin{array}{c}\text { Japan } \\
\text { benchmark }\end{array}$ & Kose et al. \\
\hline Australia & 10.8 & 52.1 & 21.3 & 27.1 & 75.1 & 19.5 & 4.5 & 51.0 & 16.1 \\
\hline HKSAR & 68.5 & 15.8 & 16.5 & 23.2 & 32.4 & 7.9 & 19.2 & 0.8 & 10.3 \\
\hline Japan & 51.5 & & 45.5 & 21.5 & & 40.5 & 66.3 & & 36.7 \\
\hline Korea & 33.3 & 37.5 & 7.8 & 22.1 & 86.8 & 13.2 & 35.6 & 7.8 & 3.0 \\
\hline Singapore & 23.1 & 42.2 & 5.2 & 46.8 & 33.2 & 4.1 & 9.2 & 3.2 & 20.6 \\
\hline Taiwan & 46.9 & 91.7 & & 49.6 & 65.9 & & 15.0 & 5.9 & \\
\hline United States & & 69.0 & 68.2 & & 86.8 & 52.8 & & 60.3 & 54.2 \\
\hline
\end{tabular}

\section{Consumption smoothing}

The time-series behaviour of private consumption can also reveal information about the nature of a country's economy. The insight of the consumption smoothing literature is that when people are forward-looking, they try to reduce the variability of consumption over their lifetime, such that expanding the capacity of people to maintain or 'smooth' consumption should reduce the dependence of their consumption on current income. The 
international corollary of this is that consumption growth between countries should become more correlated over time.

Obstfeld $(1986,1994)$ sets out a simple model to show this. ${ }^{13}$ Assume that individuals consume a composite traded good, $c$, that people can freely lend and borrow (in jargon, there is a complete market in state-contingent claims), that people can be aggregated into a representative agent in each country, and that there are $J$ countries. Each national agent maximises expected utility

$$
u_{t}=E\left[\int_{t}^{\infty} u\left(c_{s}\right) e^{-r s} d s\right]
$$

where $r$ is the constant subjective rate of time preference.

A benevolent dictator maximises a social welfare functional with fixed country weights, $w$. This yields the necessary condition for the efficient distribution of world tradeable consumption

$$
w^{i} u_{c}^{i}=w^{j} u_{c}^{j}
$$

for all $i$ and $j$ country pairs, where $u_{c}$ refers to the marginal utility of consumption. This implies that marginal rates of substitution across states of nature are equalised internationally. Obstfeld assumes a constant elasticity of substitution utility function

$$
u=\frac{1}{1-r} c^{1-r}
$$

Using Equation (7) to obtain the marginal utility of consumption for countries $i$ and $j$ and taking natural logs and the first differential of Equation (7) yields the expression

$$
\phi_{t}^{i}=\left(r^{j} / r^{i}\right) \phi_{t}^{j}
$$

where a circumflex indicates the growth rate (first difference of the log value).

If subjective time preference across countries is identical, then consumption growth rates are identical. If subjective time preference is lower in country $i$, then consumption growth is faster in country $i$ than in country $j$ : consumers in $i$ get more out of consuming now than do those in country $j$. Whatever the case, consumption growth across countries is perfectly correlated so long as time preferences are constant.

One of the main ways that people are able to insure against temporary shocks to income and thereby smooth consumption is by improving access to, or deepening, domestic and international financial markets and institutions. Under the assumptions of Obstfeld's model, therefore, an increase in the correlation of consumption growth between countries towards 1 can be interpreted as an increase in financial openness and integration.

It is probably heroic to think that a simple model can use complex data such as aggregate private consumption to provide insight into such a complex phenomenon as financial integration. But it is at least a starting point. One of the main weaknesses of the model is 
that in a stochastic world, consumption correlations could be changing because of different shocks to income. The focus in the empirical literature has then been on whether consumption has become more correlated between countries than has income.

We provide some simple tests of consumption smoothing in East Asia. Figures 3.5 and 3.6 show innovations to consumption for our Group A (1978-2001 period) and Group B (1993-2001 period) economies, purged of domestic income effects. Domestic income effects on consumption are 'washed out' by regressing private consumption growth on a constant, current income growth, the next three lags of income growth, and the lag level of income. This last variable is included to eliminate the income cointegration element in consumption. ${ }^{14}$

Table 3.9 shows the results for Group A countries. In general, income-purged consumption correlations are higher in the 1990s than in the 1980s. The average correlation in the $1980 \mathrm{~s}$ was -0.01 , compared to 0.14 in the $1990 \mathrm{~s}$. The implication is that, at least with respect to East Asia, the world is becoming a more integrated place.

Table 3.9: Correlation of Income-purged Innovations to Consumption, 1978-2001

\begin{tabular}{|c|c|c|c|c|c|c|c|c|c|c|c|c|}
\hline & \multicolumn{2}{|c|}{ AUS } & \multicolumn{2}{|c|}{$\begin{array}{l}\mathrm{HKG} \\
\end{array}$} & \multicolumn{2}{|c|}{ בJPN } & \multicolumn{2}{|c|}{ KOR } & \multicolumn{2}{|c|}{ ב SNG } & \multicolumn{2}{|c|}{ "TWN } \\
\hline & $1980 \mathrm{~s}$ & $1990 \mathrm{~s}$ & $1980 \mathrm{~s}$ & $1990 \mathrm{~s}$ & $1980 \mathrm{~s}$ & $1990 \mathrm{~s}$ & $1980 \mathrm{~s}$ & $1990 \mathrm{~s}$ & $1980 \mathrm{~s}$ & $1990 \mathrm{~s}$ & $1980 \mathrm{~s}$ & $1990 \mathrm{~s}$ \\
\hline AUS & & & & & & & & & & & & \\
\hline HKG & -0.27 & 0.09 & & & & & & & & & & \\
\hline JPN & -0.04 & 0.18 & 0.05 & 0.10 & & & & & & & & \\
\hline KOR & -0.25 & 0.24 & 0.03 & 0.44 & 0.09 & -0.03 & & & & & & \\
\hline $\mathrm{SNG}$ & 0.08 & -0.04 & 0.01 & 0.39 & 0.02 & 0.02 & -0.31 & 0.18 & & & & \\
\hline TWN & 0.16 & 0.09 & -0.22 & 0.21 & 0.10 & 0.25 & -0.00 & -0.06 & 0.06 & 0.22 & & \\
\hline USA & -0.02 & 0.21 & 0.04 & 0.03 & 0.04 & 0.19 & -0.01 & 0.00 & 0.01 & -0.01 & 0.03 & 0.14 \\
\hline
\end{tabular}

Table 3.10 shows the results for all countries in our sample set from 1993 to 2001. This time we do not have sufficient observations to talk about how these correlations evolve over time. The East Asian financial crisis is likely to have had some effect even on income-purged consumption correlations because the effect of the crisis was more than just a fall in income; it also affected the confidence that people in East Asia had in their future. This may be why there are strong positive correlations between Korea and Hong Kong SAR, Malaysia, the Philippines and Indonesia, although the lack of positive correlation between most of the ASEAN countries suggests that country-specific or idiosyncratic elements are still very important in that part of the region. What is also interesting is that correlations with the United States are generally positive and highest in the case of Japan. 
Table 3.10: Correlation of Income-purged Innovations to Consumption, 1993-2001

\begin{tabular}{|c|c|c|c|c|c|c|c|c|c|c|c|}
\hline & AUS & "HKG & IDN & JPN & KOR & MYS & "NZL & 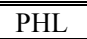 & SNG & "THL & TWN \\
\hline \multicolumn{12}{|l|}{ AUS } \\
\hline HKG & -0.05 & & & & & & & & & & \\
\hline IDN & 0.29 & -0.04 & & & & & & & & & \\
\hline JPN & 0.19 & -0.07 & 0.00 & & & & & & & & \\
\hline KOR & 0.36 & 0.56 & 0.20 & -0.09 & & & & & & & \\
\hline MYS & 0.03 & 0.30 & -0.01 & 0.06 & 0.38 & & & & & & \\
\hline NZL & 0.20 & 0.02 & 0.43 & 0.21 & 0.12 & 0.13 & & & & & \\
\hline PHL & 0.03 & -0.24 & 0.19 & 0.09 & 0.22 & 0.14 & 0.08 & & & & \\
\hline SNG & -0.05 & 0.45 & -0.36 & -0.05 & 0.16 & -0.01 & -0.42 & -0.12 & & & \\
\hline THL & -0.02 & -0.02 & -0.05 & -0.03 & -0.13 & -0.05 & 0.10 & -0.09 & 0.10 & & \\
\hline TWN & 0.04 & 0.28 & -0.23 & 0.20 & -0.05 & -0.14 & -0.08 & -0.15 & 0.19 & -0.19 & \\
\hline USA & 0.13 & -0.00 & -0.00 & 0.40 & 0.10 & 0.13 & -0.09 & 0.12 & 0.10 & -0.28 & 0.07 \\
\hline
\end{tabular}

\section{An assessment}

This paper conducts a battery of time-series tests on a reasonably big data set. What can be made of all this? We are struck by three points from these tests.

First, East Asia is not a homogeneous unit. There are elements of commonality shared by economies in East Asia. But the reach of this commonality over particular economies can vary substantially depending on which macroeconomic variable they are defined over and whether the linkages are defined as short or long term.

Consider, for example, how the economies in East Asia are clustered according to the short-term common factors in output, consumption and investment growth. With respect to output growth, the main East Asia cluster is Australia, Korea, Singapore and Taiwan, with Japan and Hong Kong SAR on the outer. With respect to consumption growth, the main East Asian cluster is Australia, Korea, Taiwan and Hong Kong SAR, with Japan and Singapore on the outer. With respect to investment, however, the main East Asian cluster is Japan, Korea, Hong Kong SAR, Singapore and Taiwan, with Australia on the outer.

Looking at the long-term or fundamental elements of commonness, the cointegration results also show different groupings within East Asia. In terms of output over the past two and a half decades, Australia, Korea and Japan share a common positive trend with the United States; only Hong Kong SAR and Singapore share a common positive trend with Japan. Australian and Korean output, private consumption and investment all share a common positive trend with the corresponding aggregate in the United States but a common negative trend with that in Japan.

Put together, one would be hard pressed to say that there has been a unique common driving economic fundamental in output, consumption or investment in East Asia over the past few decades. In terms of macroeconomic performance, Japan stands apart from much of the region, except in terms of short-term investment interactions. Overall, in economic terms at least, commonness in East Asia depends on the macroeconomic aggregate and the time frame of the linkage. 
Figure 3.5: Income-purged Innovations to Private Consumption, 1978-2001
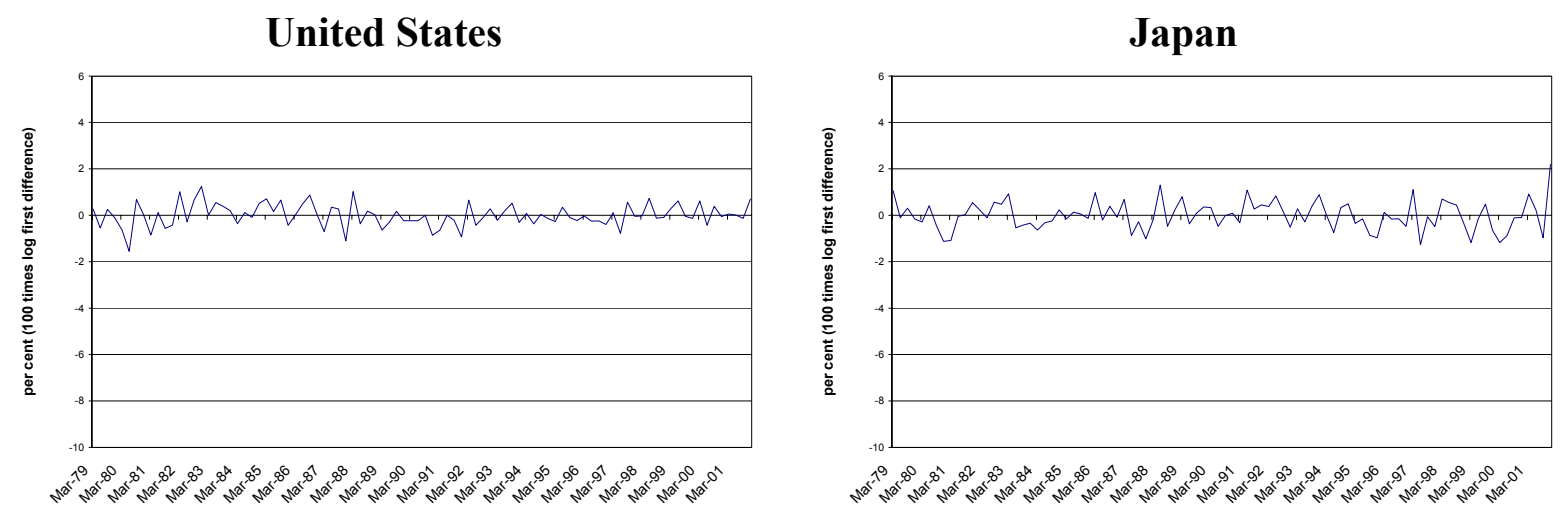

Australia

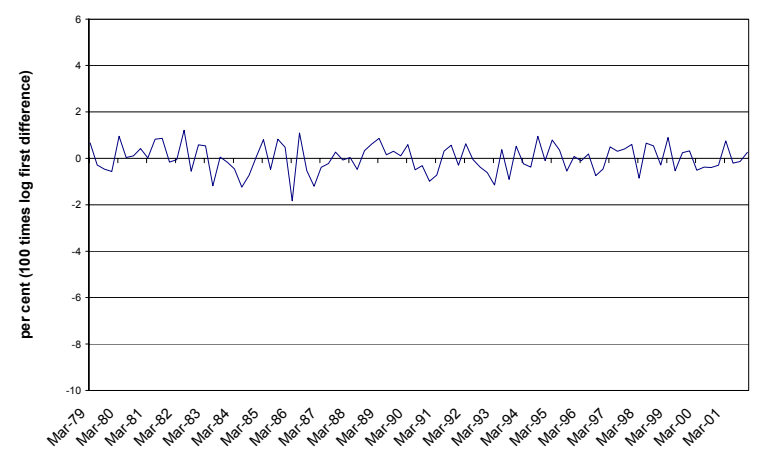

Korea

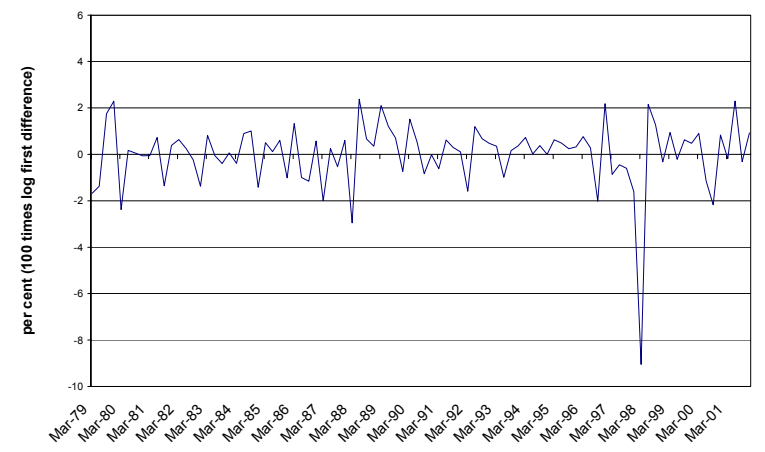

Hong Kong SAR

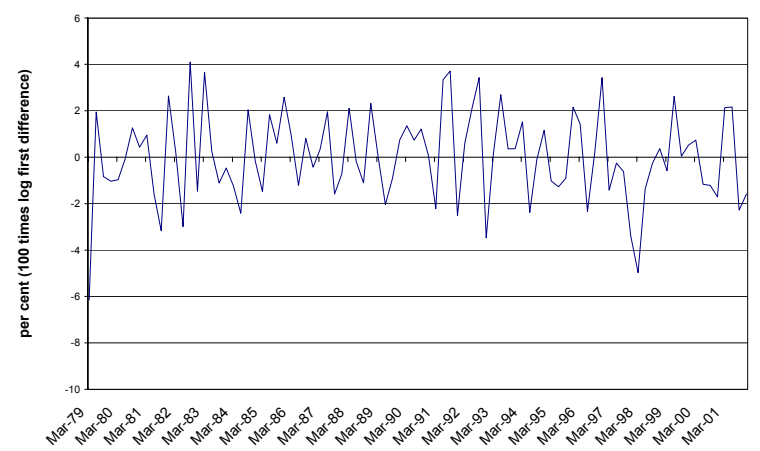

Taiwan

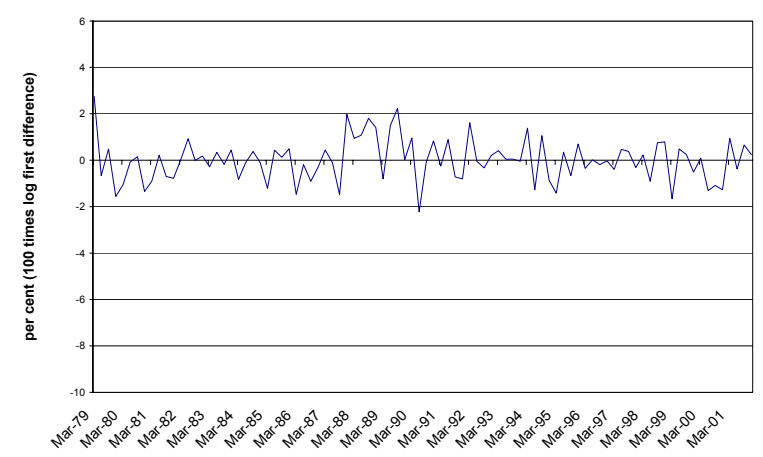

Source: CEIC database and authors' calculations. 
Figure 3.6: Income-purged Innovations to Private Consumption, 1993-2001
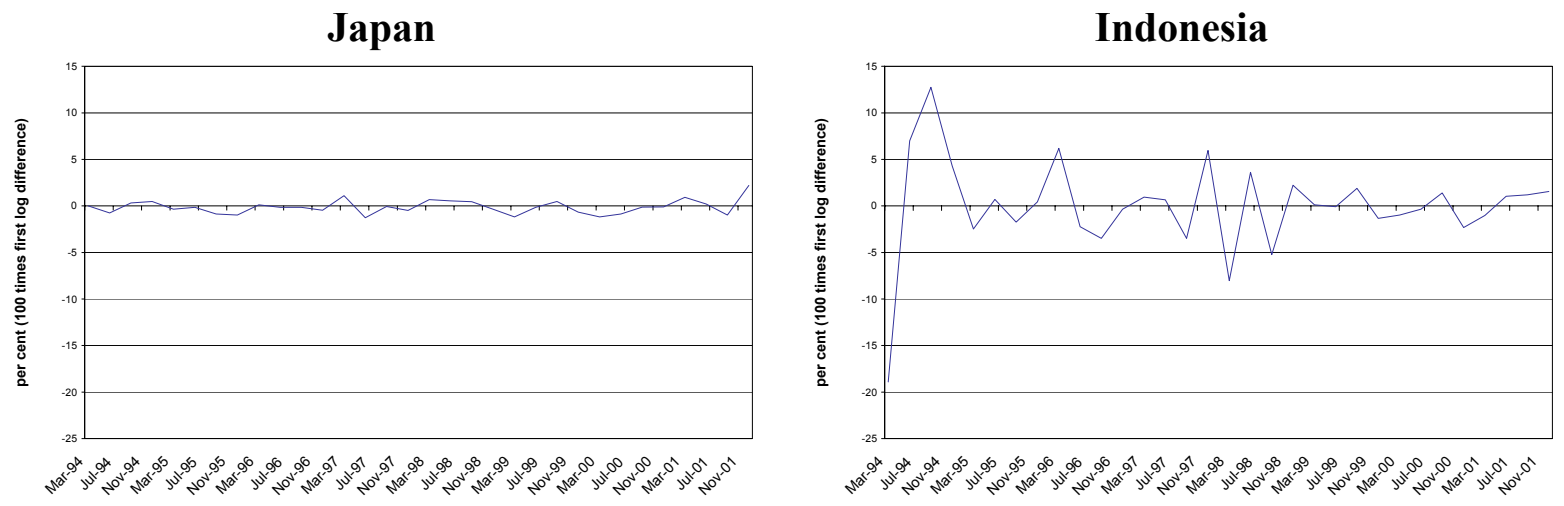

Philippines
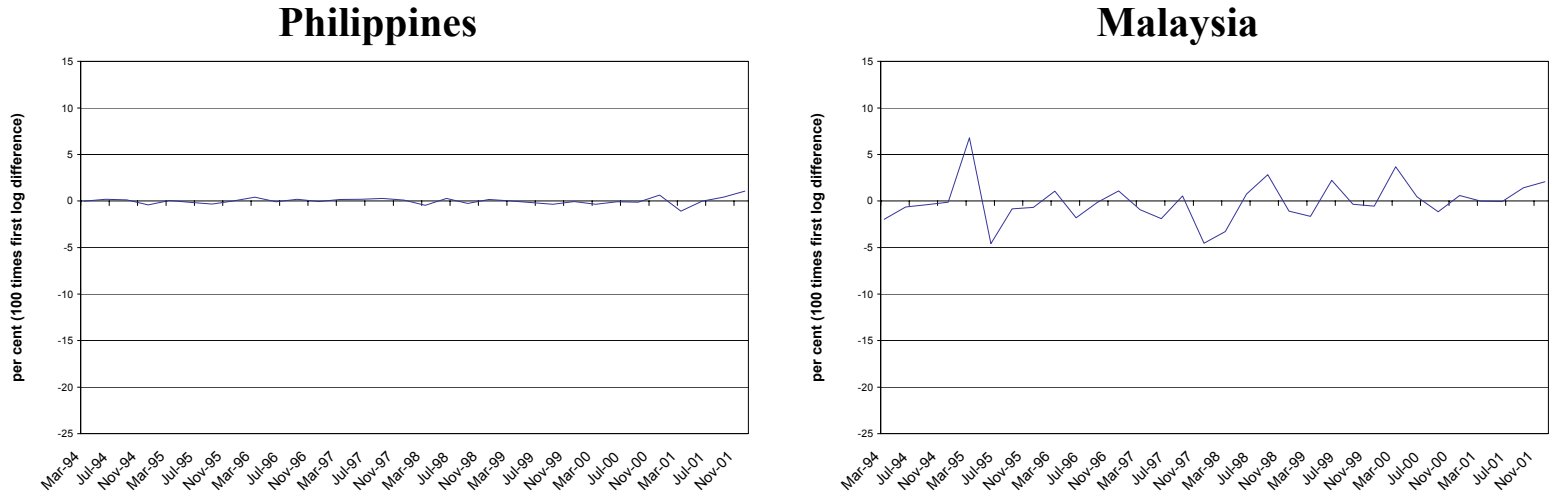

New Zealand

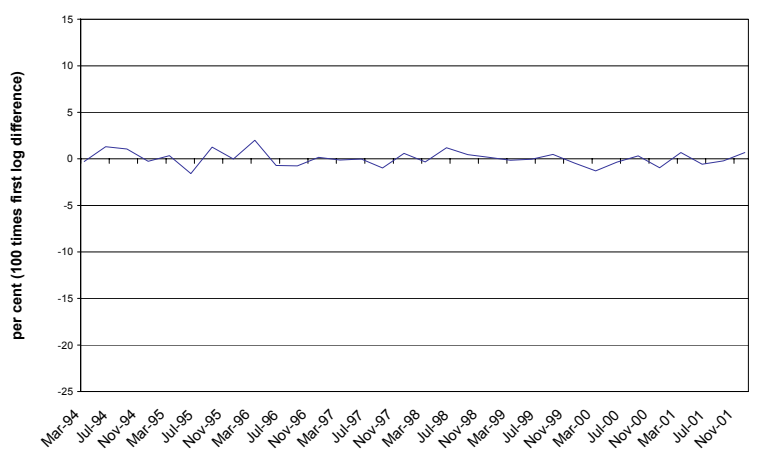

Thailand

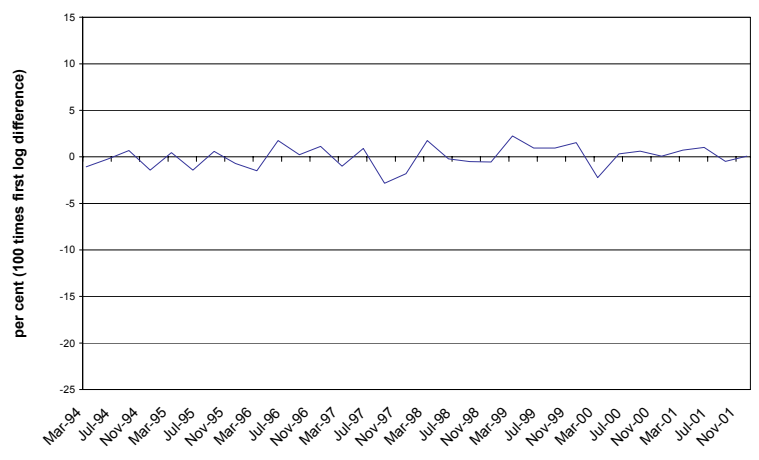

Source: CEIC database and authors' calculations.

Second, in many respects the integration that is occurring between economies in East Asia is global. This is most obvious in the pattern of commonness of East Asian economies with the United States. The United States is important for all economies in the region either in the short or long run, and in at least one key macroeconomic aggregate: output, consumption or investment.

The global orientation is also evident in the results we report on deepening financial integration in East Asia. Financial integration is fundamentally a global phenomenon since it implies financial openness not just to some regions of the world but to all; this is also an important element of non-discrimination in the General Agreement on Trade in Services (GATS) framework. The basic insight of the consumption-smoothing literature is attractive: when countries have developed, sophisticated and open financial markets 
and institutions, households have easier access to financial products that enable them to smooth consumption when there are temporary disturbances to current income.

The rising correlation of consumption growth (purged of income effects) in the region is consistent with deeper financial integration: consumption has become less dependent on current domestic income increasing the correlation of consumption innovations between countries.

In the same way, the strength of the common factor in consumption growth can also be interpreted as a test of financial integration in East Asia. Figure 3.7 below shows Part B of Figure 3.4 along with the estimated common factor when Korea is used as the benchmark for consumption growth. While this removes the direct effects of Korean consumption growth from the common sample, it means that the common group includes both Japan and the United States. Given the insights of the consumption-smoothing literature, this should provide us with an indication of the degree of financial openness in economies to the region and the world: the stronger the common factor, the more financially integrated and open is the economy.

Figure 3.7: Common Factors in Private Consumption

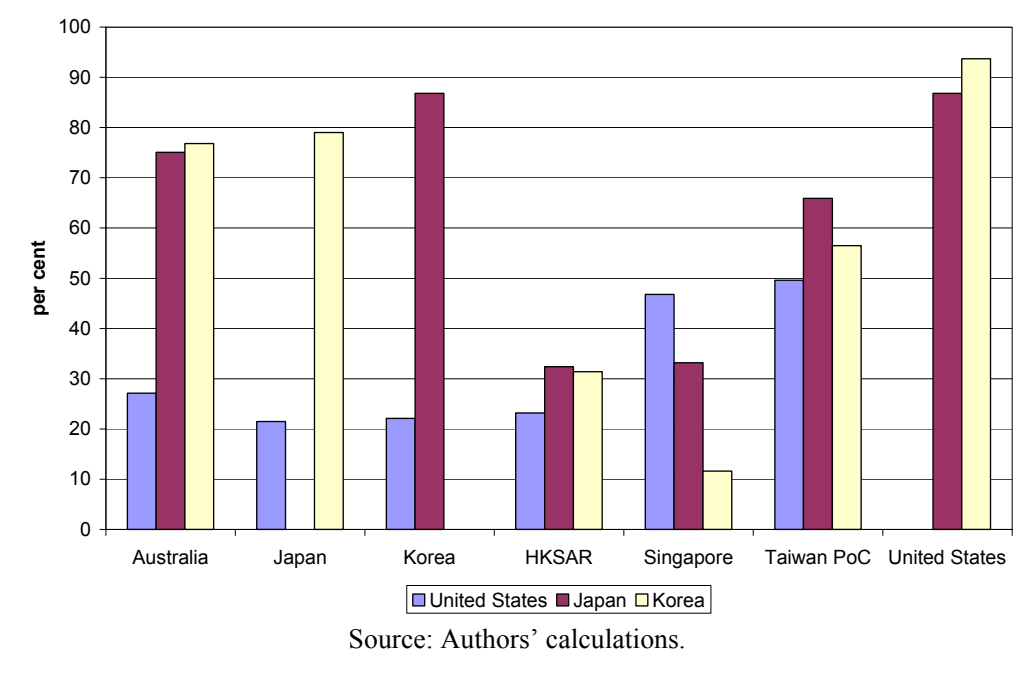

The striking result is that the common factor in consumption growth is relatively high for Australia, Japan, Korea, Taiwan and the United States. For all these economies except Taiwan, these common factors are substantially stronger than for national income. Viewed from the perspective of the consumption-smoothing literature, the strength of the common factor in consumption growth is strong evidence of a high degree of financial integration or development and openness in these economies.

So why are the common factors for Hong Kong SAR and Singapore so weak in relative terms? Both these economies are strong regional financial centres in East Asia but, at least for most of the sample period, their own domestic financial markets and institutions have been relatively repressed; only in recent years have they started to liberalise and internationalise their domestic financial systems. ${ }^{15}$ It is not surprising that, compared to the other economies in this small sample, they have the lowest common factor in 
consumption growth and hence least evidence of financial integration. In short, the results make sense and contribute to the literature on financial integration.

The common factors under different benchmark specifications also suggest that there are limits to intra-regional consumption smoothing. The common factors in consumption are notably smaller (except for Singapore) when the United States is used as the base, meaning that the factors are restricted to the rest of the region. When the benchmark is Japan or Korea, the factors include the United States, and the common factors are relatively high. The result that common factors in consumption are generally high only when the United States is included suggests that the region as a whole is too small to enable full consumption smoothing. Consumption smoothing is maximised by global interaction and openness. If this is right, then the implication is that the region needs to retain and indeed develop its outward global orientation.

Third, the result that commonality across output, consumption and investment is far from complete may suggest that there is scope for policy action to advance integration. Of course there may be an irreducible amount of idiosyncrasy in economic outcomes. And some forms or degrees of cooperation may not yield better outcomes in all cases. These are the stuff of further research. But what is striking with the results here is the overriding idiosyncrasy in domestic investment.

In thinking about a constructive agenda for deeper regional integration in East Asia, the deep idiosyncrasy of investment suggests that there may be large gains from greater focus on ways to improve and deepen investment links in the region. Given the importance of financial factors in determining investment, a constructive agenda for promoting deeper economic integration would focus on strengthening, deepening and harmonising financial, legal and market infrastructure in economies in the region. Building up the region's financial infrastructure - which is relatively weak in terms of risk management (reflected in the smallness of the region's derivatives markets), legal reliability and capacity, and cross-jurisdictional mutual recognition of and access by financial institutions ${ }^{16}$ - may improve the operating environment for business and investors, boost investment and deepen links in the region.

\section{CONCLUSION}

Examining the common aspects of output, private consumption and investment in East Asia over the past 25 years reveals some interesting contrasts. Although there is evidence of common trends and common factors in each of these macroeconomic variables within the region, the patterns of commonality typically differ between output, consumption and investment. There is also substantial evidence of important linkages outside the region.

The most striking regional link in East Asia is the common factor in investment growth between Japan, Korea, Taiwan and, to a lesser extent, Hong Kong SAR and Singapore. This looks like a Japanese factor. This link is less robust as a common trend: of Australia, Hong Kong SAR, Korea, Singapore and Taiwan, Japanese investment only shares a common positive trend with the last two of these economies. And the common factor in investment growth is very small compared with the idiosyncratic components in investment growth in the region. There is scope to deepen the common factor in 
investment growth in East Asia by promoting financial integration, although this has a global orientation.

Beyond the East Asian common factor in investment growth, there is little evidence of East Asian commonness in output, consumption and investment. There is no evidence of an East Asian business cycle, East Asian common trends in output, consumption and investment, or East Asian common factors in output and consumption growth. There are points of commonness in parts of the region but there are unexpected points of difference such as negative output, consumption and investment trends between Japan and Korea.

There are, however, striking elements of commonality between some economies in East Asia and beyond, notably the United States; East Asia is an outward-looking region. This is most striking in the consumption data. Correlations of income-purged consumption growth between countries increased in the 1990s over the 1980s, indicating that financial integration has increased. Common factors in consumption growth are also high for Australia, Korea, Japan, Taiwan and the United States, indicating a high degree of financial integration for these economies; it is lower for Hong Kong SAR and Singapore, reflecting the relatively recent liberalisation of these economies' domestic financial systems.

Our final analysis is that there is little evidence of common evolution in the combined set of output, consumption and investment across the region over the past 25 years, although subsets of indicators and countries contain common features. In general, the links are heterogeneous and extend beyond the region. 


\section{APPENDIX 3.1: DATA SOURCES}

The data were all extracted from $\mathrm{dX}$ data in June 2002. The data are from the CEIC database, except for the Australian data (which are from the ABS database), the New Zealand data (which are from the New Zealand Time Series database) and the US data (which are from the OECD Quarterly National Accounts database). The database codes are given as follows.

\begin{tabular}{lccc}
\hline \hline Country & GDP & Consumption & Investment (GFCE) \\
\hline Australia & SNAQ.AV\#\#\#I99GPM & SNAQ.AV\#PH\#99FCE & SNAQ.AV\#\#\#99GFC \\
Hong Kong SAR & HAKB & HACBA & HAEB \\
Indonesia & DAMA & DAMPAA & DAMPB \\
Japan & JAKP & JAKPA & JAKPCA \\
Korea & KAWA & KAWAAAA & KAWABA \\
Malaysia & MADA & MAEAB & MAEC \\
New Zealand & SNCQ.S1RB15S & SNCQ.S2RP30GS & SNCQ.S3RP51AN1110S/99S \\
Philippines & PABB & PACB & PAED \\
Singapore & SAMB & SAIA \\
Taiwan & WAVB & WAVFA & SAIC \\
Thailand & TAWA & TAVFAA & TAVFB \\
USA & USA.EXPGDP.LNBARSA & USA.EXPC.LNBARSA & USA.GFSTOT.LNBARSA \\
\hline \hline
\end{tabular}




\section{REFERENCES}

Bernard, A.B. and S.N. Durlauf (1995), 'Convergence in International Output', Journal of Applied Econometrics, 10, 97-108.

Blanchard, O. and S. Fischer (1989), Lectures on Macroeconomics, MIT Press, Cambridge MA.

Campbell, J.Y. and N.G. Mankiw (1987), 'Permanent Income, Current Income and Consumption', NBER Working Paper No. 2436. NBER, Cambridge MA.

Campbell, J.Y. and N.G. Mankiw (1989), 'Consumption, Income and Interest Rates: Reinterpreting the Time Series Evidence', NBER Macroeconomic Review, 4, $185-245$.

de Brouwer, G.J. (1999), Financial Integration in East Asia, Cambridge University Press, Cambridge.

de Brouwer, G.J. (2003), 'Financial Markets, Institutions, and Markets in East Asia', Asian Economic Panel, 2(1), MIT Press, Cambridge MA, 53-80.

Dungey, M. (1999), 'Decomposing Exchange Rate Volatility around the Pacific Rim', Journal of Asian Economics, 10, 625-635.

Dungey, M. and R. Fry (2001), 'International Shocks on Australia - The Japanese Effect', manuscript, Australian National University, Canberra.

Dungey, M., R. Fry, B. Gonzalez-Hermosillo and V.L. Martin (2002) 'International Contagion Effects from the Russian Crisis and LTCM Near-collapse', IMF Working Paper No. 02/74. IMF, Washington D.C.

Dungey, M. and V.L. Martin (2001), 'Contagion across Financial Markets: An Empirical Assessment', paper presented to NYSE Conference on Global Equity Markets, Hawaii, February.

Gruen, D. and G. Stevens (2000), 'Australian Macroeconomic Performance and Policies in the 1990s', in D. Gruen and S. Shrestha (eds), The Australian Economy in the 1990s: Proceedings of a Conference, Reserve Bank of Australia, Sydney, $32-72$.

Hansen, L.P. (1982), 'Large Sample Properties of Generalized Method of Moments Estimators', Econometrica, 50, 1,029-1,054.

Kose, A., C. Otrok and C. Whiteman (2000), 'International Business Cycles: World, Region, and Country-specific Factors', manuscript, University of Virginia.

Obstfeld, M. (1986), Capital Mobility in the World Economy: Theory and Measurement', Carnegie-Rochester Series on Public Policy, 24, 55-104. 
Obstfeld, M. (1994), 'International Capital Mobility in the 1990s', CEPR Discussion Paper No. 902.

Obstfeld, M. and K. Rogoff (1999), Foundations of International Macroeconomics, MIT Press, Cambridge MA.

Turnovsky, S. (1999), International Macroeconomic Dynamics, MIT Press, Cambridge MA.

$1 \quad$ See Blanchard and Fischer (1989), Obstfeld and Rogoff (1999) and Turnovsky (1999).

2 See Campbell and Mankiw (1989), Bernard and Durlauf (1995) and Kose, Otrok and Whiteman (2000).

3 Estimation is done in Eviews 4.1.

4 If the equations are normalised on Australia, for example, the only significant common trend is with the United States.

5 If we estimate just one cointegrating vector, the relationship between US and Japanese consumption is negative but statistically insignificant.

6 If we estimate just one cointegrating vector (normalised on the United States or Japan), the relationship between US and Japanese investment is negative but statistically insignificant, the relationship between US and Korean investment is positive and significant, and the relationship between Japanese and Korean investment is negative and statistically insignificant.

$7 \quad$ Estimation is done in EViews.

$8 \quad$ See, for example, Campbell and Mankiw (1987, 1989).

$9 \quad$ See Gruen and Stevens (2000).

10 Estimation is done in Gauss 3.5 using the OPTMUM module and standard convergence criteria.

11 The model in Equation (1) can be extended to consider common effects across consumption, output and investment, akin to the model proposed in Dungey and Martin (2001) for financial markets. This model can also be identified with moment conditions from six countries. However, empirical investigations revealed that no solution could be obtained for these data, implying that there is insufficient separate identification of the factors. In particular, the evidence suggests that the country and common effects are not sufficiently separated. This is consistent with the findings reported later that the three variables are characterised differently; given that common trends are evident for consumption and output, but not investment, this result is perhaps not unexpected.

$12 \quad$ See Dungey and Fry (2001).

13 See also Obstfeld and Rogoff (1999) and Turnovsky (1999). This description follows de Brouwer (1999).

14 Regressions are done using EViews.

15 See de Brouwer (1999).

16 See de Brouwer (2003). 